\title{
La violencia, que nos toca a todos: una mirada desde la historia del maltrato en la escuela
}

Maria Teresa Prieto Quezada*

\section{Resumen}

¿Porqué contar la propia vida? ¿Para qué sirve? Señala De Gaulejac (2005) que a las personas les gusta hablar de ellas mismas, contar su propia vida. Incluso cuando ésta no es bella, tiene el sentimiento de decir cosas importantes. Muchas veces en esta búsqueda se juega una posición social, el intento de encontrar ancestros prestigiosos para revalorizarse uno mismo, ahora cada uno, incluso la "pequeña gente", se interesa en su historia. Esto nos remite a una vieja pregunta que los filósofos conocen muy bien: ¿De dónde vengo? ¿Quién soy? Hoy en día cada individuo debe luchar por tener un lugar social y poseer una existencia social e individual. Cada individuo es invitado a volverse autónomo, a producir su existencia. Quiere decir que la existencia social ya no está dada tanto por el grupo, como en la sociedad de otros tiempos, sino remitida a cada individuo que es invitado a construirse, a devenir él mismo. Pero ¿en qué consiste este proceso de construcción de sí mismo? ¿Qué quiere decir afirmar su identidad hasta producir su vida? Estas preguntas planteadas por la sociología clínica son claves para iniciar el análisis de un caso de maltrato escolar, a través del recorrido por momentos clave de su historia de vida.

Palabras clave: Violencia escolar. Historia. Maltrato. Acoso escolar.

\section{A violência que toca a todos nós: uma perspectiva a partir da história do maltrato na escola Resumo}

Por que contar a própria vida? Para que serve? De Gaulejac (2005) assinala que as pessoas gostam de falar de si mesmas, contando a sua própria vida. Inclusive quando esta última não é bela, têm o sentimento de dizer coisas importantes. Muitas vezes esta busca envolve uma posição social, a tentativa de encontrar ascendentes prestigiosos

\footnotetext{
* Licenciada en Sociología; doctora en Educación por la Universidad de Guadalajara; coordinadora de Investigación y Posgrado del Centro Universitario del Norte de la Universidad de Guadalajara, ha escrito artículos relacionados con el tema de violencia escolar, conflictos y acuerdos de convivencia, prevención y atención al maltrato en niños y adolescentes. Es miembro del sistema Nacional de Investigadores en México.
} 
para valorizar a si mesmas. Todos, inclusive os jovens, têm interesse na sua história. Isto nos remete a antigas indagações, bem conhecidas pelos filósofos: De onde venho? Quem sou eu? Hoje em dia cada indivíduo deve lutar para obter uma posição social e ter uma existência social e individual. Cada indivíduo é convidado a se tornar autônomo e a produzir a sua existência. Assim, a existência social já não é dada tanto pelo grupo, como na sociedade de outrora, porém é dirigida a cada indivíduo, solicitado a construir-se a si mesmo. Entretanto, em que consiste este processo de construção de si mesmo? Que significa afirmar a sua identidade até "produzir" a sua vida? Estas indagações suscitadas pela sociologia clínica são estratégicas para iniciar a análise de um caso de maltrato escolar, por meio de momentos cruciais da história de vida.

Palavras-chave: Violência escolar. História de vida. Maltrato. Bullying.

\section{Violence that concern all of us : a perspective from the history of maltreatment at school Abstract}

Why should we talk about our own lives? What is it useful for? De Gaulejac (2005) says that people enjoy talking about themselves, telling about their own lives. Even if it is not beautiful, they have the feeling to talk about relevant stuff. Many times during this quest, the social status plays an important role: the attempt to find prestigious ancestors to enhance themselves. Everyone, even young people are interested in their family stories. This leads us to philosophical questions: Where do I come from? Who am I? Nowadays, every individual must strive to achieve a social position and get a social and individual existence. Every individual is invited to become independent to 'produce' his/her existence. That means that the social existence is no longer given by the group as in societies in ancient times but by the individual invited to build and become himself. So, what is this process of building himself about? What does 'assert their identity until producing life' mean? These questions raised by the clinical sociology are keys to begin the school bullying analysis by crucial moments of someone's life story.

Keywords: School violence. Life history. Abuse. Bullying.

\section{La historia de vida: una herramienta para acceder a la comprensión del maltrato entre iguales}

Entre los científicos sociales que utilizan la herramienta señalada en el título de este apartado, por ejemplo, dentro del método biográfico, la meta más deseable y dificil de alcanzar es conseguir hallar las circunstancias que permitan realizar una buena historia de vida. Esto implica no sólo conseguir un buen informante, que esté inmerso en el universo social que estamos estudiando, sino que tenga además una buena historia de vida, en términos del interés demarcado por el objeto de estudio. 
Se requiere un relato que sea narrativamente interesante y que sea completo, lo que depende enteramente de las características del sujeto elegido: que sea brillante, genuino, sincero, que se explique con claridad e introduzca en sus relatos elementos amenos, que sea autocrítico y que analice con una cierta perspectiva su propia trayectoria vital y sobre todo, que sea constante y esté dispuesto a llegar hasta el final. Sin todos estos requisitos es difícil que el investigador se decida a ensayar esta forma de documento científico, la historia de vida. Este criterio orienta la elección de uno de los informantes cuyo relato se analiza con mayor detalle en este trabajo, a tal grado que puede constituir el referente empírico principal sobre el cual se base la investigación.

La historia de vida es el relato autobiográfico obtenido por el investigador mediante entrevistas sucesivas, en las que el objetivo es mostrar el testimonio de un sujeto, donde se recogen tanto los acontecimientos como las valoraciones que dicha persona hace de su propia existencia. En la historia de vida, el investigador es solamente el inductor de la narración, su transcriptor, y también el encargado de retocar el texto, tanto para ordenar la información del relato obtenido en las diferentes sesiones de entrevista, como el responsable de sugerir al informante la necesidad de cubrir los huecos informativos olvidados. En la etapa de publicación de la narrativa, el investigador podrá, según las circunstancias, hacer retoques ulteriores al texto.

A nivel metodológico, el relato de vida, se expresa en tres dimensiones esenciales de la identidad: los deseos, las angustias inconscientes y la sociedad a la cual pertenece su autor, con la dinámica existencial que lo caracteriza.

Todo relato implica una reconstrucción, y sobre este punto los psicoanalistas y los sociólogos concuerdan de buen grado con los literatos. La historia de vida es "tiempo recompuesto" por la memoria (DE GAULEJAC, 2002). Sin embargo, en opinión de este autor, hay que advertir cierta relatividad en las versiones del sujeto, dado que no nos podemos fiar de la memoria. Obedece a lógicas distintas que la verdad o la ciencia. Olvida, deforma, transforma, reconstruye el pasado en función de las exigencias del inconsciente, de presiones circundantes, de las condiciones de producción del relato, de estrategias de poder del locutor y del entrevistador, entre otras.

El relato tiene, pues, múltiples facetas, igual que una novela, sea autobiográfico o no. Es a la vez un testimonio y un fantasma. Las palabras dicen lo que ha pasado ("Es la realidad") pero también transforman esa realidad ("No son más que palabras"), aunque sólo fuera porque cambian la relación del sujeto con esta realidad. Hablando de "su" historia, el individuo la (re)descubre. Es decir, hace un trabajo sobre él mismo que modifica su relación con esa historia. 
En suma, la historia de vida comprende dos aspectos:

- Designa lo que "realmente" ha pasado durante la existencia de un individuo (o de un grupo), es decir, el conjunto de acontecimientos, los elementos concretos que han caracterizado e influenciado la vida de este individuo, de su familia y de su medio;

- Designa la historia que se cuenta sobre la vida de un individuo lo de un grupo), es decir, el conjunto de relatos producidos por él mismo y/o por otros sobre su biografía.

Publicar una historia de vida presupone condiciones de adecuación científica, pero también propiamente textual o literaria. Por esto son tan pocos los relatos de vida recogidos que llegan a presentarse finalmente como narraciones autobiográficas, porque hay que señalar, salvo raras excepciones, que los sociólogos, antropólogos o psicólogos sociales no buscan realizar historias de vida como estudios de caso únicos, sino que éstas surgen a menudo, a posteriori, después de meses o incluso años de estar trabajando en un determinado tema.

La aportación de esta herramienta al estudio del objeto, reside, entre otras, en las siguientes posibilidades:

- Introduce en profundidad en el universo de las relaciones sociales primarias. A través del relato de vida es posible desplazar fácilmente el foco de análisis hacia las relaciones familiares, hacia las pautas de formación y funcionamiento de relaciones del sujeto a lo largo de distintas etapas y en diversos contextos, como en el caso de esta investigación, las relaciones entre compañeros de escuela.

- Proporciona un control de los factores que explican el comportamiento de un individuo dentro de un grupo primario, que representa el nivel esencial de mediación entre el individuo y sociedad. Este control se puede ejercer no solamente a través de la narrativa del sujeto, sino que puede complementarse con las referencias a las personas que constituyen este entorno social inmediato.

- Constituye material valioso para conocer y evaluar el impacto de las transformaciones, su orden y su importancia en la vida cotidiana, no sólo del sujeto, sino de sus grupos de referencia (familia, escuela, amigos, trabajo).

- En la etapa de publicación de los resultados de una investigación, la historia de vida es la mejor ilustración posible para que el lector pueda penetrar empáticamente en las características del universo estudiado.

\section{Las vias de acceso a la historia de los sujetos}

La importancia de recuperar "las vidas cotidianas" de los niños y jóvenes alumnos que han vivido maltrato, radica principalmente en recuperar la historia de sujetos particulares, que producen y reproducen y resisten esas vivencias, lo que significa recuperar la materialidad histórica del maltrato y la violencia que se genera en la escuela y describir la heterogeneidad de los procesos que vivieron los actores en el ámbito de convivencia entre alumnos. 
En virtud de lo anterior, el trabajo de recopilación de datos que se realizó en este estudio tuvo como instrumento principal la entrevista, orientada por un conjunto de ejes diseñados para poder reconstruir los aspectos fundamentales de la vida de los sujetos que aportan a la comprensión de su experiencia en relación con el "maltrato entre iguales".

Teniendo en cuenta que en el maltrato entre alumnos la participación y la percepción que sobre éste tienen los actores no inician y terminan en la escuela, resultó indispensable acercarse a los contextos de la historia de los sujetos elegidos, hasta desembocar en su análisis a profundidad. Para esto fue significativo un caso cuya complejidad, evidenciada en la propia narración del sujeto, sivvió para un acercamiento más preciso a su papel en las situaciones de maltrato entre iguales, desde distintos antecedentes de su historia que convergen para comprender su posición ante estas situaciones.

Los ejes sobre los cuales giró la entrevista se indican enseguida:

Familia. Como parte de este eje se interrogó a los sujetos sobre datos como su edad, sus antecedentes familiares, el lugar que ocupan en su familia, las características de los otros miembros, en particular de los padres, y la interacción del sujeto con éstos y con otras figuras de referencia (hermanos, tíos). En este eje se aborda, como se ha discutido en párrafos anteriores, la forma en que la historia familiar incide en la percepción y en los comportamientos actuales del sujeto ante situaciones de maltrato por parte de sus iguales.

Escuela. En este eje se recupera información en torno a la ubicación de los alumnos en la escuela, desde los datos generales relacionados con el semestre en que se encuentran, hasta los especificos del estudio, que tienen que ver con la relación que tienen con sus compañeros, la historia que han tenido como estudiantes, y la actuación ante situaciones reales o potenciales de maltrato entre alumnos, tratando de explicar cómo han evolucionado a partir de que las percibieron, desde etapas tempranas en las que han sido estudiantes. Vida Cotidiana. Este eje contempló la indagación en torno a las personas y acontecimientos que rodean al sujeto y conforman escenarios con los cuales se encuentra familiarizado. Se incluye la descripción que éste hace de sus amigos, de los espacios en los cuales tiene convivencia fuera de la familia y la escuela, así como de sus gustos y aficiones. Este tipo de datos orienta la atención hacia partes significativas en la constitución de la subjetividad, de donde se pueden extraer elementos para interpretar su discurso, en el estudio de su posición en situaciones de maltrato entre alumnos. 


\begin{abstract}
Maltrato entre alumnos. Este eje es el más importante, toda vez que concentra la información directamente relacionada con el objeto de estudio. En él se aborda con los sujetos la identificación que logran de distintas formas de violencia al interior del espacio escolar en el cual conviven cotidianamente, para desembocar en la exploración de sus percepciones sobre los referentes concretos del maltrato entre alumnos, tales como las agresiones físicas, verbales, las formas de burla o rechazo (comúnmente llamadas por ellos "carrilla"), las relaciones de poder que aprecian, la forma en que participan en estas situaciones (basada en el esquema agresor-víctima-observador) y el impacto de ellas en quienes son considerados como víctimas.
\end{abstract}

El análisis de los datos recopilados por vía de la entrevista, se recupero en cuatro momentos sucesivos:

1. Construcción de una narrativa de base que permite un acercamiento suficiente a la historia de vida del sujeto.

2. Detección de los significados asignados por el sujeto a los personajes y a los hechos presentes en la historia construida, que representen datos potencialmente explicativos de su posición ante el maltrato en la escuela.

3. Inferencia de factores asociados a las situaciones de maltrato vividas en la escuela, tanto los que tocan al sujeto como los de naturaleza exógena.

4. Valoración de los efectos del maltrato sobre el sujeto, de acuerdo con los roles en que se posiciona ante el fenómeno a lo largo de su historia.

\title{
El individuo como producto, actor $y$ productor de historia. El caso central del análisis.
}

¿Por qué contar la propia vida? ¿Para qué sirve? Señala De Gaulejac (2005) que a las personas les gusta hablar de ellas mismas, contar su propia vida. Incluso cuando ésta no es bella, tienen el sentimiento de decir cosas importantes. Muchas veces en esta búsqueda se juega una posición social, el intento de encontrar ancestros prestigiosos para revalorizarse uno mismo, ahora cada uno, incluso la "pequeña gente", se interesa en su historia. Esto nos remite a una vieja pregunta que los filósofos conocen muy bien: ¿De dónde vengo?, ¿Quién soy?

Hoy en día cada individuo debe luchar por tener un lugar para poseer una existencia social e individual. Cada individuo es invitado a volverse autónomo, a producir su existencia. Quiere decir que la existencia social ya no está dada tanto por el grupo, como en las sociedades de otros tiempos, sino remitida a cada individuo que es invitado a construirse, a devenir él mismo. Pero ¿en qué consiste este proceso de construcción de sí mismo? ¿Qué quiere decir afirmar 
su identidad hasta producir su vida? Estas preguntas planteadas por la sociología clínica son claves para iniciar el análisis de un caso de maltrato escolar, a través del recorrido por momentos clave de su historia de vida.

\section{La novela familiar de Pedro}

En la historia de vida de Pedro, el sujeto elegido para profundizar en el análisis, en ocasiones terminan por confundir las vivencias afectivas, emocionales, personales e intimas, con aquello que está, por así decirlo, fuera de él, en los elementos de los contextos social, económico, laboral, ideológico, cultural y familiar en donde se ha desenvuelto. De considerar esta multirreferencialidad proviene, entonces, una serie de preguntas teóricas y metodológicas acerca de cómo abordar esta totalidad, cómo descifrar lo que hay de objetivo y subjetivo, cómo analizar un relato, a partir de qué referentes, con cuáles pautas metodológicas, qué tipo de relación se instala entre el investigador y el narrador, cómo comprender el conjunto de factores que intervienen en las condiciones de producción del relato de la historia de vida.

Todo esto remite a una hipótesis: el individuo es producto de una historia de la cual intenta volverse sujeto. ¿Qué quiere decir que el individuo es el producto de una historia? ¿De qué historias estamos hablando? Esto se puede comprender de distintas maneras.

En primer lugar, el individuo es producido por la historia. Su identidad se ha construido a partir, por un lado, de acontecimientos personales que ha vivido, que forman la trama de su biografía. Historia singular, única. Pero, al mismo tiempo, estos elementos son comunes a la historia de su familia, de su cultura, de su medio social, de su clase de pertenencia, de la sociedad en la cual vive. Entonces el individuo es un ser sociohistórico. Los individuos son producidos por la sociedad.

En segundo lugar, el individuo es un actor de la historia. A la vez que ha sido producido, es también su productor. Como portador de historicidad el sujeto tiene la capacidad de intervenir sobre su propia historia y esto, lo posiciona como sujeto.

Finalmente, el individuo es productor de historia, en el sentido de que él cuenta historias y se cuenta historias a si mismo. De Gaulejac (2005) sostiene, en ese sentido, que cuando uno se cuenta historias a sí mismo, se trata siempre de cuentos, en tanto se posiciona en un escenario donde convive lo que el sujeto es con lo que quiere representar en su imaginario. Uno podría interrogarse entonces sobre la función de contarse historias. Ello nos lleva a la cuestión de la memoria y la transmisión. En particular, remite a las familias, como antecedente inmediato en la construcción de historias. ¿Cómo se cuenta a los otros la historia de la familia? ¿Qué quieren decirse unos a otros? ¿Qué es lo 
que se prefiere no decirles? Los relatos tienen como función transmitir al otro lo que sucedió, y al mismo tiempo transformar aquello que sucedió en función de aquello que uno desea o ha deseado. En la manera de contar las historias de familia, uno les ofrece a los otros un guión de vida como lo hace la víctima de maltrato que se proyecta en esta investigación:

Como descubrirás, o confirmarás, tengo un miedo patológico al abandono (Mi padre me abandonó al morir cuando yo tenía 2 años, y mi madre me abandonó, primero para cuidarlo a él en su agonía y luego para trabajar y mantener a la familia, creo que una gran parte de mi conflicto se originó entonces, nunca pude perdonarles eso). De modo que no me abandones, si realmente lograra sanar, podria hacer tantas cosas, me he pasado la vida, viéndola desde una fría vitrina: eso no es vida (PEDRO).

La historia de Pedro se empaña con la muerte de su padre, que era un sostén emocional importante para su vida. De manera tajante, el abandono simbólico y real de su padre y de su madre han sido una constante en su historia de vida.

Realmente no recuerdo a mi padre. Mi primer recuerdo es del día que él murió, pero no lo recuerdo a él, sólo el cielo nublado, aguardando en una casa ajena mientras alguien nos dice que mi padre se fue al cielo, pero yo lo único que vi fue nubarrones grises, ese es el recuerdo de un niño de 2 años y un mes...Posterior a su desaparición fuimos a dar a la casa de mi tía Rosa y su esposo Jaime. Ella, una mujer caprichosa y frustrada, él un tipo bonachón; un tanto bruto y, desgraciadamente superado por los caprichos de su mujer. Si bien por referencias, fotografias y demás fuentes alternas he llegado a la conclusión que también mi padre era dominado por mi madre. Había ciertas diferencias entre él y mi nuevo ejemplo de masculinidad (TIO JAIME),

En la historia de Pedro sus ascendentes - de modo especial, su padre - jugaron un papel muy importante, al grado de que conoce e interpreta muchas de sus características. Entre otras, llama la atención su referencia al papel del poder en las relaciones que capta desde temprana edad:

Mi padre fue un hombre bajito, simpático, relativamente guapo, de voz dulce (fue cantante aficionado), carácter cortés (blando); y por lo que dicen, siempre rodeado de amigos. Eso me lleva a pensar que no tenia muchos problemas para conocer mujeres, y si bien al casarse, mi madre ejerció sobre él, un papel dominante, al menos su unión significó para él una conquista, y para ella un trato razonable, mi madre, no siendo una mujer realmente bella, si tenía un carácter definido, su padre fue un gran ejemplo para ella, hasta la muerte de éste, cuando ella contaba con 13 años de edad. Su padre, mi abuelo Alejandro, era 
proveniente de una familia fuerte en la ranchería donde ella nació. Alejandro era el carpintero del pueblo y era, según dicen algunos, una de las personas más cultas del lugar. Sin embargo, mi abuelo tenía un problema congénito; una ulcera varicosa en la muñeca de la mano izquierda, que estaba tullida, y de la cual sólo podía usar 2 dedos.

Como refleja la evidencia anterior, Pedro fue delimitando sus propios hallazgos en los que se fue descubriendo su propia historia de maltrato, reconstruyendo de alguna manera una visión crítica del maltrato, en la que crea juicios de valor, atisba hipótesis y recrea el espacio vivido. Se podría decir que lo que es cotidiano para otros, para Pedro resulta ser un objeto de análisis y reflexión profunda de los fenómenos que le ocurren, los cuales son atípicos en los jóvenes de su edad.

Es suposición mía, pero intuyo que esa limitación afectó a su seguridad a la hora de elegir pareja [...] según lo que he escuchado todos dan a entender en sus relatos que mi abuela Angélica era de una personalidad más limitada que mi abuelo. De ella tengo menos datos. Dicen que físicamente era idéntica a mi tía-Ogro, Rosa, que era gruñona, rencorosa, pero eso sí, buena cocinera (Eso Rosa, no lo heredó, sus comidas sabían a rayos [...] otro dato interesante es que el padre de mi abuela, según cuentan, cuando llegaron los revolucionarios a su ranchería para enrolarlo, se metió en su cama y se murió del miedo.

Cuando mi abuelo Alejandro murió a los 49 años, Angélica se volvió loca y se dejó morir de tristeza un mes después. Mi madre se quedo totalmente huérfana a los 13 años. Con todo y sus limitaciones, yo pongo a mi madre del lado de los valientes, y a mi tía Rosa del lado de los cobardes.

Como se aprecia, el sujeto detalla de manera muy fina historias familiares que manifiestan "juicios y prejuicios" sentimientos y emociones muy ocultos de la familia, incluyendo algunos datos íntimos que expresan los significados que le impregna a las interpretaciones de los otros, por ejemplo en las decisiones que tomó su madre respecto a quien sería su pareja, o en su descripción de belleza y fealdad que le da sentido a su propia identidad, familiar y personal. Esto se realiza a través de las construcciones existentes entre el sujeto en sus conflictos y preguntas relacionadas con su historia.

Luego de pasar mil desventuras mi madre tuvo varios novios y al que más quiso fue a uno de nombre Raúl, profesionista y de mejor clase que ella, a 2 semanas de su boda mi madre canceló la boda al notar que la madre de Raúl le podía hacer la vida imposible, rechazó también por lo menos a otros 2 hombres, cuando conoció a mi padre vio a un 
hombre bueno y aceptó casarse con él, no por despecho, o prisas, simplemente creyó que era el momento y que su vida al lado de el sería más fácil que sola (ambos tenían 25 años).

Mi padre por su parte, parecía necesitar una mujer más fuerte que él y por eso, supongo, escogió a mi madre, con su mentón duro y su mirada decidida, que contrastaba con el mentón de mi padre, ligeramente más suave, y sus ojos soñadores. Ellos vivieron casados 6 años, y según cuenta mi madre, fueron los años más tranquilos de su vida.

Pedro proporciona información muy importante de su vida familiar. En su narración, resulta muy revelador el tipo de experiencias cotidianas que ha vivido, las cuales interpreta desde una posición notablemente reflexiva, incluyendo términos como las relaciones de poder, donde la indefensión y las prerrogativas derivadas de la autoridad de algunos de los miembros de su familia se asumen como parte natural de la interacción que describe, al tiempo que distingue las contradicciones imperantes en esas relaciones, o en las que tuvieron lugar en otros contextos.

En contraste, la pareja que nos terminaría "dando su ejemplo" era ampliamente más disfuncional. Mi tío Jaime es un ranchero al que 50 años en la ciudad no han cambiado (ni para bien ni para mal), no creo que tuviera muy buena estrategia con las mujeres y a los 40 años se encontró con Rosa de 30 que venia de un noviazgo roto y súbitamente aceptó casarse con él.

En esa casa, mandaba ella, peor aún, una de sus prácticas era en las reuniones de la familia, comentar "a forma de broma" cómo él cometía bruteces, y luego terminaba diciendo, "pobre Jaimito, es como un niño". Si bien siento que la he perdonado por la pinche infancia que me dio, me encabrona sobremanera cuando aún en las reuniones hoy en día hace eso con él ¿Qué no se da cuenta que está humillando a su hombre todo el tiempo?

Si bien Jaime tenía muchas cualidades; era físicamente fuerte; trabajador y, nunca se supo imponer a su mujer (para lograr el equilibrio). Nunca vimos en esa casa una verdadera relación de pareja: jamás". Él nunca me enseñó las reglas de un deporte [...] para ejemplificar la relación revisemos dos pasajes:

Cuando yo tenía 5 años, no teniendo ejemplo de actividades masculinas decidi hacerle un regalo a Jaime, yo mismo, para la Navidad. Agarre un trapo y le bordé un pato, el regalo era "un pañuelo". El día de Navidad esperé a que él llegara y cuando fue al baño se lo puse afuera de la puerta y le grité 
que le había dejado un regalo en el suelo. Él salió y no vio el pañuelo, lo pisó y se fue: Lloré inconsolablemente, quizás fue, solo un accidente, pero fue un incidente desafortunado.

Más o menos en aquellas fechas fuimos a la playa, y mi tía le pidió que me enseñara a nadar. El me llamó y me pidió que lo abrazara del cuello, acto seguido se metió como 100 metros a nado entre las olas. Cuando por fin salimos y pude escupir el agua y la arena que me había tragado [...] no me quedaron muchas ganas de entrar al mar de nuevo [...]. Con ese pinche tipo de ejemplos y apoyo.

La fragilidad y vulnerabilidad emocional en que se instaló Pedro fue un factor que no contribuyó a la búsqueda de un padre sustituto, como fue el tío Jaime, lo cual da lugar a un gran resentimiento en el sujeto hacia algunos actores de su historia familiar. Ya señalaba Heller (1993) que 3 la emoción, el sentimiento y el razonamiento están intrinsecamente entrelazados, aunque en ese sentido el punto central, no es la definición de las emociones sino su ubicación analítica dentro de la construcción social, es decir, los elementos que reporta Pedro ayudan a entender sus sentimientos y emociones en el margen cotidiano de la vida, que es donde adquieren sus sentido y existencia, donde Pedro se identificó consigo mismo y alcanzó a ver sus diferencias con los demás.

La historia de Pedro se relacionó directamente con la muerte su padre, el abandono involuntario de su madre y su encuentro necesario con los tíos que lo cuidaron durante gran parte de su infancia y constituyó una serie de encrucijadas sociales y efectos psicológicos de tipo familiar (que le habian robado la historia para protegerlo), los cuales desembocaron en episodios que se describen en las siguientes narraciones, en las que destaca:

El resentimiento a la familia que lo acogió, por permanentes amenazas a su persona siendo un niño atemorizado y que instantáneamente se convirtió en odio hacia sus tíos y que manifiesta en el siguiente relato:

Otro punto importante y algo que exigiría a los Padres es ¡Nunca amenacen a sus hijosi Actúen, pero no amenacen. La maldita perra de mi tía cada que yo "me comportaba mal", se dirigía al teléfono y hacía como que marcaba, luego me decía que la gente del internado ya venía por mi y que me iban a apartar de todos (la separación que más me dolía era de mi hermana).

El miedo. Esta emoción considerada como un área reservada a la esfera personal es expresada por Pedro como un factor que trastocó su vida y su acceso al mundo escolar, generando comportamientos confusos y 
contradictorios dentro de su personalidad que lo llevan a momentos de gloria estudiantil pero que súbitamente lo trasladan al infierno. En la explicación de este fenómeno, afirma Luna Zamora (2005) el miedo es un estado mental no saludable que genera al individuo que lo experimenta un estado emocional desequilibrante que puede predecir y explicar conductas posteriores.

Estamos hablando de un niño de 5 o 6 años cuyo padre murió 3 años atrás y cuya madre trabaja todo el día. Eso no era humano [...] Te enseñan a vivir con miedo [...] Durante mis primeros años de escuela, era un niño a la vez iracundo y autoritario, como frágil y temeroso. La mayoría de mis maestros tenían quejas sobre mi carácter. Aún así mi inteligencia natural y mi apego a la lectura me permitieron tener sólo una vez un 8 (segundo de primaria) el resto 9's y 10's.

Casi cada satisfacción que tuve, fue resultado del talento o de la suerte, de mis ejemplos directos tuve muchas ausencias y decepciones ¿Entiendes la magnitud que fue para mi ganar ese concurso en $6^{\circ}$. Año de primaria? El último apoyo que tuve académicamente en casa fue para hacer planas de palitos y bolitas. A los 8 o 9 años ya podía darles clases a mis familiares de cómo interpretar la Biblia y quizás desde antes ya dibujaba mejor que ello.

Pedro continúa con su narración, reconociéndose como víctima de maltrato, que nos permite hacer reconocible la subjetividad del actor de esta trama.

Conforme fui creciendo me di cuenta que mis talentos no eran para nada tan grandes como yo creí en mi niñez. Sin embargo, dado que ellos fueron mi única fuente de satisfacción: ¿Cómo demonios no iba a ser egomaníaco? Poco o nada obtuve de mis relaciones con la mayoría de la gente y menos con mis compañeros de grupo, pero de mis discursos inventados saqué para ver al presidente por mis buenas calificaciones.

Hay un vínculo entre la historia social, la historia familiar y los conflictos psicológicos de este joven, quien por otra parte enfrenta el vacío con un egocentrismo poco típico de la edad. De Gaulejac (2005) apunta en este sentido que la historia es actuante y condiciona las conductas, las maneras de ser, las actitudes y las personalidades. Para comprender de qué manera la historia es actuante, es necesario establecer el vínculo con la manera en que es confrontada por un individuo. Pero también es necesario analizarla como el eco individual de una trayectoria familiar y social en un contexto histórico dado.

Una acotación muy importante que hace este autor para alguien que quiere hacer un análisis desde la sociología clínica es que el inconsciente no es un concepto que exista sólo en el ámbito del psicoanálisis. También nos remite, por ejemplo, a 
la teoría del habitus de Bourdieu, término con el que se refiere a una suerte de programas históricamente montados, que le indica al individuo maneras de ser y maneras de hacer, manera de conducirse en situaciones dadas, maneras de incorporarse a la historia. Es decir, una capacidad de adaptarse a una situación nueva reviviendo y reproduciendo maneras de ser y maneras de hacer.

Esto explica en parte el gran ego que Pedro identificaba en su personalidad, que atribuía a su habilidad como mitómano, con "discursos inventados" para conseguir ciertos fines que le permiten compensar todo el vacío que lo caracterizaba.

Las debilidades de Pedro se convierten en un momento de su historia en fortaleza y le permitieron ciertos satisfactores, los cuales posteriormente fueron contraproducentes en el desarrollo de personalidad en la adolescencia. Esto conduce a preguntar si se trata de una especie de contradicciones de naturaleza social o psicológica, si son contradicciones interrelacionales o fallas sistémicas en el seno de la familia. Es necesario analizar lo anterior como el eco individual de una historia donde ya se manifestaba la agresión en un contexto histórico dado de Pedro como lo muestra la siguiente viñeta:

\footnotetext{
Creo que la primera vez que alguien me golpeó fue con mis primos, y fue un primo menor que yo. En esos tiempos recurría a mi madre o mi hermana, ya que nunca confié en mis tíos: a mi tía le tenía miedo y a mi tío aunque bonachón jamás le tuve confianza, nunca hubo un acercamiento con él, ese "click" que se necesita para iniciar una relación con alguien [...] Ciertamente no sé, si mi exacerbada cobardía es aprendida o si ya está intuida en mis genes, lo cierto es que el contraste entre mi parte cobarde y la otra que siempre ha aspirado a una libertad salvaje y plena han creado un nudo en el centro de mi personalidad, el cual no he tenido la paciencia, ni la entereza de desanudar, para convertirlo en un motor: cosa que sí logran hacer muchas otras personas, para llegar a su destino, incluso desde posiciones más desfavorables que la mía [...].
}

Pedro desde la familia ya recibía malos tratos. Ante eso, él se concibe cobarde y no sabe si explicarlo como una conducta biológica o socio-histórica, resultado de sus vivencias personales y su experiencia de vida.

La discusión sobre la forma de concebir las estructuras mentales y de experiencia que moldean las percepciones de los sujetos está guiada, en la perspectiva de De Gaulejac (2005) por la cuestión de la predominancia entre la influencia del contexto social o del aparato psíquico individual. De acuerdo con este autor, para Bourdieu, lo que él Ilama las estructuras mentales son una especie de caja negra en la cual hay una 
interiorización de la exterioridad, una interiorización de las estructuras sociales. Con Freud y el psicoanálisis, por otra parte, se presenta un esquema completamente distinto, en el cual lo intrapsíquico es totalmente autónomo e independiente de toda situación social o cultural. Entonces, uno de los problemas que se nos plantea en las historias de vida, es cómo poder llegar a atar los dos cabos.

\section{La historicidad de Pedro}

Cada individuo actúa sobre él mismo al desarrollar su capacidad de ser sujeto; si uno no cambia la historia, porque lo pasado es pasado, uno puede al menos cambiar la manera en que este pasado es actuante en uno mismo. En esta tónica habla De Gaulejac (2005) de una frase de Heidegger donde definía la historicidad escribiendo: "La historia no quiere decir 'el pasado', en el sentido de aquello que ha ocurrido, sino de aquello que advierte. Lo que tiene una historia esta en relación con un devenir. Entonces lo que tiene una historia puede al mismo tiempo hacer una historia". Hay aqui una concepción dinámica de la historia. Aquel que no tiene historia, que no posee historia, tampoco puede hacer una historia.

Lo anterior se constata en argumentos que expresa Pedro al interpretar y comprender qué le había sucedido, por qué se encontraba en ese momento histórico y las circunstancias que lo rodeaban, siempre en la búsqueda como si estuviera poseído por aquello que le había sido extraído.
[...] mi madre compró un pequeño departamento, muy lejos de donde vivía mi tía Rosa, y un día nos dijo que al terminar, yo la primaria, y mi hermana la secundaria, nos mudaríamos para allá. Por mucho tiempo fue sólo una idea abstracta, pero en abril, en vez de ir a inscribirme a la Secundaria, que era la más cercana, mi madre me llevó a la otra, que era "la mejor" de las cercanas a la nueva casa. No me imaginaba yo que el ogro es un espíritu que puede encarnarse en múltiples cuerpos, o, quitando el estilo poético mamón: que una víctima siempre encontrará sus ogros, esté donde esté.

Aunque Pedro advertía que era una presa fácil del maltrato en esos momentos no sabía lo que le esperaba en esa escuela. El silencio fue su compañero, parte de su personalidad y fiel acompañante guardado muy celosamente. Estos secretos de familia, escuela y vida cotidiana fueron expresados años posteriores cuando él consideró que de alguna manera las heridas ya estaban sanadas. Pedro tardó muchos años en contar a alguien el drama que le tocó vivir, haciendo un análisis profundo de su vida infantil y juvenil.

La siguiente parte del relato permite apreciar que alcanza a distinguir, dentro de su marco de referencia, la figura del agresor, como componente innegable de las situaciones de violencia temprana que reporta, y al maltrato como una 
realidad inevitable, que impacta su subjetividad generando cierto tipo de disposiciones, como el aislamiento y la fantasía:

En contraste, al ser golpeado por mis compañeros de secundaria, en mi vida personal me trataba de ver reflejado en los personajes de televisión, digamos, Batman, Schwarzenegger. Por aquel tiempo 1998 (Nos habiamos mudado y el ejemplo de mi tío quedó distante [...] aunque ya de por sí era muy distante [...] había una serie de televisión "El guerrero del camino": fui a la peluquería y pedí el mismo corte que el protagonista. En el caso de mi grupo de secundaria el dumping, si bien grande [...] hoy analizándolo a la distancia, era de reacciones exageradas, es decir, una buena cantidad de mis compañeros se empeñaban en decir que yo era el más débil, feo e inepto [...] yo parcialmente lo creí. Sin embargo la reacción de ellos, más que estar basada en un juicio objetivo, recibía mucho de su combustible de la fuerza del rechazo, es decir: una parte de mí se esforzaba aparentar la perfección y la superioridad sobre mis colegas, al carecer de los medios para hacerlo, la lógica reacción de ellos fue iNo eres perfecto cabrón! (Lo cual era cierto), para luego ser proseguida por ¡De hecho eres el peor de todos, no eres nada! Si en todas las sociedades a la figura del héroe sigue de un proceso de admiración, viene otro de rechazo y ataque. En mi caso, siendo tan pocos mis elementos heroicos, a un brevísimo periodo de aceptación siguió la maratónica crucifixión.

La subjetividad recuperada en la experiencia vivida por Pedro permitió comprender a un humano creativo, crítico, evaluador y actor del mundo social, que nos remite a una comprensión más compleja de los fenómenos sociales. Enríquez citado por Taracena (2002) señala que la narración de sí mismo es siempre un relato para otros y que de ese modo la individualidad encuentra un emplazamiento en una familia o en una clase.

En su historia Pedro se muestra como un excelente dibujante de si mismo, lo cual demuestra al plasmar su identidad y el modo en que la fue creando a lo largo de su vida estudiantil y cotidiana, por ejemplo en momentos donde la timidez de su infancia seguía, pero al mejorar su aspecto físico a través del endurecimiento de sus facciones, alcanzaba una ligera estabilidad. Pero la sombra de su desdicha lo revolvía a ese mundo de sombras desde donde se espejea constantemente.

\footnotetext{
Podemos vivir enfermos, metidos en armaduras oxidadas y cargando piedras gigantes siendo los últimos en darnos cuenta de ello. Así, yo vivo metido en el juego de todo esta bien, las cosas se compondrán,
} 


\begin{abstract}
"este dolor que sentí fue solo una tarde gris", pero ¿sabes? Se trata de algo más que una tarde gris, mi personalidad, es algo así como el jardín del Gigante Egoísta $^{1}$ casi siempre es invierno y cuando hay flores marchitan muy rápido.
\end{abstract}

Pedro tiene una capacidad de reflexión de su niñez poco vista en los jóvenes de su edad, donde permanentemente asume sus puntos de vista, desde una mirada crítica, tomando en cuenta motivaciones, valores, sentimientos y vanidades muy acentuadas a su personalidad. La construcción e interpretación que hace de sí mismo es implacable, siendo un juez muy justo de los actos propios y ajenos. Esta construcción es también en cierta forma un reflejo de lo que vive socialmente. Dentro de la interpretación contenida en esta construcción, existen valores en choque, por ejemplo, con relación a la belleza, en tanto los asigna a sí mismo, pero también como defensa frente a sus debilidades en confrontación con la realidad. Entre la aportación a los datos producto de la visión que tiene de sí mismo y la que reporta de los demás, la balanza se inclina hacia lo primero, lo cual puede ser resultado de su capacidad introspectiva, más que del olvido por los otros actores.

\title{
Conclusión
}

El maltrato que se ejerce en la familia y en la escuela a niños y adolescentes por parte de familiares, maestros y de compañeros entre algunos, tiene un destinatario privilegiado, el otro. Emana del vínculo, hace patente el carácter humano y cultural de la violencia, que evoca una variedad de acciones asociadas a la agresión física, a la destrucción del otro o de sí mismo, a la degradación simbólica del semejante, a la exclusión y el desconocimiento, a las modalidades del sometimiento, a la implantación de los imperativos y las regulaciones, a las estrategias de visibilidad y vigilancia, a la invalidación y valoración de un grupo de individuos, por la vía de infringir un dolor o ejercer la exclusión hasta el límite de la desaparición.

La violencia y la agresión no son nuevas, ni en el mundo ni en la escuela, pero las formas que adoptaron a partir de los últimos años indican que no estamos frente a más de lo mismo, sino que nos enfrentamos a un fenómeno con nuevas y variadas manifestaciones. La violencia no sólo es un problema de cantidad sino de calidad del acto.

El estudio del maltrato entre alumnos no solo implica considerar el entramado que conforman los agentes que conviven en el espacio escolar, sino que

1 Se centra en un cuento infantil cuyo autor es Oscar Wilde (1942). 
también responde a un contexto familiar, ya que es una realidad que adopta múltiples formas y que se da en muchas direcciones, entre estos agentes y los que conviven con ellos fuera de la escuela.

En este trabajo, uno de los principales intereses ha sido explorar el mundo de la subjetividad de los niños y jóvenes que viven violencia, donde se han dicho cosas que serían imposibles, impensables e incomprensibles bajo la mirada de otro paradigma. Desde el punto de vista metodológico resulto de gran utilidad la posición de la Sociología Clínica que permitió al sujeto estudiado mencionar e identificar sus propias experiencias desde la subjetividad y el dolor.

Comprender el sentido del dolor que tienen algunos niños y jóvenes en sus relaciones familiares y escolares, es comprender el sentido de una vida sin violencia. En el caso del maltrato entre iguales no hay una objetividad del dolor sino una subjetividad que concierne a la entera existencia del ser humano, sobre todo en su relación con los otros y que se ha construido en el transcurso de la historia personal, las raíces familiares, sociales y culturales. Una subjetividad también vinculada con la naturaleza de las relaciones entre quien ha vivido el maltrato y quienes lo rodean.

Estudiar la violencia que se presenta en contextos escolares es pisar territorios nuevos, donde se confunden las vivencias afectivas intimas con elementos de contexto social y familiar, ideológico y cultural donde se ha desenvuelto el sujeto, es por ello que la historia de Pedro nos toca a todos, no solo porque nos toca los sentimientos, sino también, por un compromiso y responsabilidad ética, en busca de recuperar la memoria de tantos niños y jóvenes que cotidianamente fueron lastimados y maltratados en la escuela, con el fin de resarcir el daño, por una parte y por otra prevenir, dando herramientas a futuras generaciones para que disminuya o se eliminé el impacto que puede tener la violencia en la vida escolar. Como padres de familia, profesores, intelectual, directivos o ciudadano común, tal vez ha llegado el momento de trabajar juntos ante este fenómeno tan devastador en nuestras escuelas. 


\section{Referências}

DE GAULEJAC, V. Historia de vida, psicoanálisis y sociología clínica. Querétaro:

Ed. Cultura y Conciencia, 2005.

DE GAULEJAC, V. Lo irreducible social y lo irreducible psíquico, Perfiles Latinoamericanos, v. 10, n. 21, México, 2002.

HELLER, A. Historia de la vida cotidiana. México: Grijalbo, 1993.

LUNA ZAMORA, R. Sociología del miedo: un estudio sobre aminas, diablos y elementos naturales. Universidad de Guadalajara, 2005.

TARACENA, E. La construcción del relato de implicación en las trayectorias

profesionales. Revista Perfiles Latinoamericanos, Mexico, n. 21, p.121-141, 2002. 